\title{
Sorptive properties of aluminium ions containing mesoporous silica towards L-histidine
}

\author{
Joanna Goscianska ${ }^{1} \cdot$ Izabela Nowak $^{1} \cdot$ Anna Olejnik $^{1}$
}

Received: 15 October 2015/Revised: 22 November 2015/ Accepted: 24 November 2015/Published online: 8 December 2015

(C) The Author(s) 2015. This article is published with open access at Springerlink.com

\begin{abstract}
The applicability of aluminium-containing mesoporous materials as carriers for L-histidine has been evaluated for the first time. The modified mesoporous silica such as SBA-15 and SBA-16 were synthesised by hydrothermal method and characterised by low-temperature nitrogen sorption, transmission and scanning microscopy, X-ray and laser diffraction methods. The results of these studies confirmed the ordered mesoporous structures of all materials obtained. The modification of mesoporous materials with aluminium ions changed the textural parameters and particle size distribution relative to those in the pristine material. Aluminium-modified SBA-15 exhibited higher release rate of amino acid than the pure material. The opposite phenomenon was observed when L-His was released from pristine and modified SBA-16 materials. The kinetics of amino acid release from all mesoporous materials followed the Korsmeyer-Peppas model. The results proved that the structural parameters of mesoporous materials and the percentage content of aluminium strongly influenced the release rate of L-His.
\end{abstract}

Keywords Mesoporous materials - Mesoporous structure · Amino acid · Adsorption/desorption · Korsmeyer-Peppas model $\cdot$ Release kinetics models

Anna Olejnik

annamar@amu.edu.pl

1 Faculty of Chemistry, Adam Mickiewicz University in Poznań, Umultowska 89, 61-614 Poznań, Poland

\section{Introduction}

The ordered mesoporous materials have been the subject of studies at many research centres all around the world. They display a number of attractive properties, among them the presence of pores of diameters ranging from 2 to $50 \mathrm{~nm}$, well developed surface area $\left(600-1000 \mathrm{~m}^{2} / \mathrm{g}\right)$, wellordered, tuneable pores and nontoxicity (Feng et al. 2008; Hudson et al. 2008; Blumen et al. 2007). The materials have found a wide range of applications in catalysis (Taguchi and Schüth 2005; Sobczak et al. 2006), electronics (Walcarius 2015), in biological and medical fields (Chen et al. 2013; Mai and Meng 2013; Mamaeva et al. 2013) and in adsorption processes (Perego and Millini 2013; Taguchi and Schüth 2005). Pure mesoporous materials show low chemical activity, which restricts their applications. An easy method of activation of mesoporous materials is introduction of heteroatoms such as aluminium, boron or transitions metals. Their introduction causes an increase in the properties of mesoporous materials, increase in the number of acidic centres and the ability to exchange ions, which extends the possibilities of their application in e.g. heterogeneous catalysis and in the adsorption processes. Another method for the activation of mesoporous materials is the introduction of metal ions into or on the pore walls. Two methods of introduction of heteroatoms are known. The first is the so-called direct synthesis, in which the heteroatoms are added directly to the precursor of silicon, which binds the heteroatoms in situ in the structure of the material formed. In the second method, the so-called post-synthesis modification, at first the mesoporous material is obtained and then heteroatoms are grafted into it, so that heteroatoms are introduced into the mesopores structures (Hoffmann et al. 2006). As the $\mathrm{Al}^{3+}$ cation radius is $0.51 \AA$, which is close to that of $\mathrm{Si}^{4+}$ 
cation of $0.42 \AA$, the atom of silicon can be easily exchanged by aluminium one. Knowing that the properties of aluminium compounds depend on their environment, the $\mathrm{pH}$ are of key importance in the process of mesoporous materials modification with aluminium. Aluminium has been for the first time introduced into the mesoporous material MCM-41 by Luan et al. (1995), in order to increase the number of acidic centres and consequently, the catalytic activity. The same group has used the post-synthetic method of modification to introduce aluminium to SBA-15 (Luan et al. 1999). It has been reported that the incorporation of aluminium into mesoporous silica enhances the hydrothermal stability of mesoporous materials (Hussain et al. 2014; Xia and Mokaya 2004). Furthermore, the modification of their surface by introducing aluminium ions can generate a new adsorption centres that can influence the loading and release process of various biomolecules such as amino acids. So far L-phenylalanine has been adsorbed on various pure ordered mesoporous silica (Goscianska et al. 2013a, b). In other study, basic amino acid, lysine has been adsorbed on MCM-41 (O'Connor et al. 2006). Another scientific group has investigated the sorption behaviour of five selected amino acids such as glutamic acid, arginine, phenylalanine, leucine, and alanine on mesoporous materials (SBA-15, Al-SBA-15, $\mathrm{CH}_{3}(10 \%)$-SBA-15, and $\mathrm{CH}_{3}(20 \%)$-SBA-15) (Gao et al. 2008). We have found that L-histidine has been so far adsorbed on mesoporous carbon CMK-3 (Vinu et al. 2006) and $\mathrm{C}_{\mathrm{SBA}-16}$ and $\mathrm{C}_{\mathrm{SBA}-15}$ (Goscianska et al. 2013c). Up to date, there have been a few publications concerning the potential application of modified ordered mesoporous silica for L-histidine adsorption. Therefore, in this study, the pure and modified mesoporous materials were used to study the loading and release of L-His. The aim of this work was to compare the sorption properties of aluminium-containing mesoporous silica such as SBA-15 and SBA-16 towards Lhistidine.

\section{Experimental}

\subsection{Synthesis of SBA-15 and SBA-16}

\subsubsection{Preparation of SBA-15}

SBA-15 material was synthesised of $10 \mathrm{~g}$ of triblock polymer Pluronic $\mathrm{P}-123,70 \mathrm{~cm}^{3}$ of $2 \mathrm{M}$ hydrochloric acid, $150 \mathrm{~cm}^{3}$ of distilled water and $20 \mathrm{~g}$ of tetraethyl orthosilicate (TEOS). The triblock copolymer was dissolved in a solution of hydrochloric acid at $55^{\circ} \mathrm{C}$, on stirring. Then $20 \mathrm{~g}$ of TEOS was introduced drop wise. The contents were subjected to stirring by a magnetic stirrer at $55{ }^{\circ} \mathrm{C}$ for $8 \mathrm{~h}$. The precipitate and the solution were placed in a drier at $100{ }^{\circ} \mathrm{C}$ for $16 \mathrm{~h}$. The product was filtered off when hot, dried, refined and calcined at $550{ }^{\circ} \mathrm{C}$ for $8 \mathrm{~h}$.

\subsubsection{Preparation of SBA-15 modified with aluminium ions}

The materials $\mathrm{Al}(30) \mathrm{SBA}-15$ and $\mathrm{Al}(60) \mathrm{SBA}-15$ were synthesised using $10 \mathrm{~g}$ of Pluronic P-123 copolymer, $70 \mathrm{~cm}^{3}$ of $2 \mathrm{M}$ hydrochloric acid, $150 \mathrm{~cm}^{3}$ of distilled water and $20 \mathrm{~g}$ of tetraethyl orthosilicate. Plutronic P-123 was dissolved in a solution of hydrochloric acid at $55^{\circ} \mathrm{C}$, on stirring until complete dissolution. Then $20 \mathrm{~g}$ of TEOS and aluminium isopropoxide in the amounts $0.65 \mathrm{~g}$ or $0.33 \mathrm{~g}$, were introduced drop wise, so that the $\mathrm{Si} / \mathrm{Al}$ ratio was 30 or 60 . The content was stirred by a magnetic stirrer at $55^{\circ} \mathrm{C}$ for $8 \mathrm{~h}$. The precipitate with the solution were placed in a drier at $100{ }^{\circ} \mathrm{C}$ for $16 \mathrm{~h}$. The product was filtered off when hot, dried, refined and calcined at $550{ }^{\circ} \mathrm{C}$ for $8 \mathrm{~h}$.

\subsubsection{Preparation of SBA-16}

SBA-16 was synthesised using $3 \mathrm{~g}$ of Pluronic F-127 copolymer, $9 \mathrm{~cm}^{3}$ of hydrochloric acid $(37 \%)$ and $144 \mathrm{~cm}^{3}$ of distilled water. The components were stirred on a magnetic stirrer at $35{ }^{\circ} \mathrm{C}$ until complete dissolution of the copolymer. Then $9 \mathrm{~cm}^{3}$ of $n$-butanol was added and the stirring was continued for the next hour. After that time, a portion of $13.2 \mathrm{~g}$ of tetraethyl orthosilicate was added. The contents were stirred by a magnetic stirrer for $24 \mathrm{~h}$ at $35{ }^{\circ} \mathrm{C}$, and then placed for $24 \mathrm{~h}$ in a drier at $100{ }^{\circ} \mathrm{C}$. The product was filtered off when hot, dried, refined and calcined at $550{ }^{\circ} \mathrm{C}$ for $8 \mathrm{~h}$.

\subsubsection{Preparation of SBA-16 modified with aluminium ions}

$\mathrm{Al}(30)$ SBA-16 and $\mathrm{Al}(60)$ SBA-16 were synthesised using $3 \mathrm{~g}$ of Pluronic F-127 copolymer, $9 \mathrm{~cm}^{3}$ of hydrochloric acid and $144 \mathrm{~cm}^{3}$ of distilled water. The components were stirred by a magnetic stirrer at $35^{\circ} \mathrm{C}$ until complete dissolution of the copolymer. Then $9 \mathrm{~cm}^{3}$ of $n$-butanol were added and the stirring was continued for another hour. After that time, $13.2 \mathrm{~g}$ of tetraethyl orthosilicate and 0.014 or $0.007 \mathrm{~g}$ of aluminium isopropoxide were added so that the $\mathrm{Si} / \mathrm{Al}$ molar ratio was 30 or 60 . The whole content was stirred by a magnetic stirrer for $24 \mathrm{~h}$ at $35^{\circ} \mathrm{C}$, and then placed for $24 \mathrm{~h}$ in a drier at $100{ }^{\circ} \mathrm{C}$. The product was filtered off when hot, dried, refined and calcined at $550{ }^{\circ} \mathrm{C}$ for $8 \mathrm{~h}$.

\subsection{Sample characterisation}

\subsubsection{Powder X-ray diffraction (XRD)}

All the samples obtained were characterised by powder $\mathrm{X}$-ray diffraction using a D8 Advance Diffractometer made 
by Bruker with the copper $\mathrm{K}_{\alpha 1}$ radiation $(\lambda=1.5406 \AA$ ). The XRD patterns were recorded at room temperature with a step size $0.02^{\circ}$ in the small-angle range.

\subsubsection{Nitrogen sorption}

The pore structure of the samples obtained was characterised on the basis of low-temperature nitrogen adsorption-desorption isotherms measured on a sorptometer Quantachrome Autosorb iQ. Prior to adsorption measurements, the samples were degassed in vacuum at $300{ }^{\circ} \mathrm{C}$ for $2 \mathrm{~h}$. The $\mathrm{N}_{2}$ isotherms were used to determine the specific surface areas using the standard BET equation in the relative pressure $\left(\mathrm{p} / \mathrm{p}_{0}\right)$ from 0.05 to 0.2 and the cross-sectional area of nitrogen molecule of $0.162 \mathrm{~nm}^{2}$. Pore sizes were obtained from the $\mathrm{N}_{2}$ adsorption branch, using the Barret-Joyner-Halenda (BJH) method with the corrected Kelvin equation, i.e. KJS-BJH method at the maximum of pore size distribution (Kruk et al. 1997). Moreover, the $\alpha_{\mathrm{s}}$ plot analysis (Jaroniec et al. 1999) was performed for all obtained samples for the evaluation of the micropore volume. The single-point total pore volume was obtained from the amount adsorbed at $\mathrm{p} / \mathrm{p}_{0}=0.98$.

\subsubsection{Transmission electron microscopy (TEM)}

For TEM measurements, powdered samples were deposited on a grid with a perforated carbon film and transferred to a JEOL 2000 electron microscope operating at $80 \mathrm{kV}$.

\subsubsection{Particle size distribution}

Particle size distribution of materials obtained was measured by Mastersizer 2000 (Malvern UK) equipped with a Hydro dispersion unit. The samples were dispersed in distilled water and introduced into the camera optical unit. The results were obtained in the form of percentages of $\mathrm{d}(0.1) . \mathrm{d}(0.5)$ and $\mathrm{d}(0.9)$ which are defined as:

- $\mathrm{d}(0.1)(\mu \mathrm{m})-10 \%$ of the particle distribution is below this value.

- $\mathrm{d}(0.5)(\mu \mathrm{m})$ - median of particle distribution $(50 \%$ of the distribution above this value and $50 \%$ below it).

- $\mathrm{d}(0.9)(\mu \mathrm{m})-90 \%$ of the particle distribution is below this value (Goscianska et al. 2015).

\subsubsection{Scanning electron microscopy (SEM)}

SEM images were obtained using a scanning electron microscope (SEM) made by PHILIPS (Netherlands) in the following conditions: working distance of $14 \mathrm{~mm}$, accelerating voltage of $15 \mathrm{kV}$ and digital image recording by DISS.

\subsection{L-Histidine sorption studies}

L-His adsorption process was performed by solvent evaporation technique $(5 \mathrm{mg}$ L-histidine/100 $\mathrm{mg}$ silica). Mesoporous silica materials were added into $5 \mathrm{~cm}^{3}$ of L-His solution in potassium phosphate buffer $\mathrm{pH}$ 7.5. Then the solvent was evaporated. The loaded materials were then filtered off and dried for $24 \mathrm{~h}$.

Desorption studies were performed with the use of an USP Apparatus 2 (Agilent Technologies DS 708). The mesoporous material with adsorbed L-histidine was placed in an Enhancer cell. In order to maintain appropriate experiment conditions and constant surface area the mesoporous silica materials were sandwiched between two porous synthetic nets. The analysis was carried out in potassium phosphate buffer $\mathrm{pH} 7.5$ maintained at $37.0 \pm 0.5^{\circ} \mathrm{C}$ and stirred at $100 \mathrm{rpm}$. The concentration of the desorbed L-histidine was spectrophotometrically monitored at $208 \mathrm{~nm}$.

\subsection{Release kinetics calculations}

The release results were fitted with different kinetics models such as zero order ( $\%$ L-His release vs. time), first order (log of \% L-His remaining vs. time), Higuchi's model (\% L-His release vs. square root of time), KorsmeyerPeppas model (log of \% L-His release vs. $\log$ time). For each model $\mathrm{R}^{2}$ values (coefficient of correlation) were calculated. In the Korsmeyer-Peppas model, the $n$ value was used to characterise the release mechanism of active compound as described below:

- $\mathrm{n}<0.5(0.45)$-quasi-Fickian diffusion,

- $\mathrm{n}=0.5(0.45)$-diffusion mechanism,

- $0.5<\mathrm{n}<1$-non Fickian diffusion,

- $\mathrm{n}=1$ (0.89)—case II transport (zero order release),

- $\mathrm{n}>1$ (0.89)—super case II transport (Sahoo et al. 2012; Dash et al. 2010).

\section{Results and discussion}

\subsection{Structural characterisation of mesoporous materials}

All obtained mesoporous materials were characterised to determine their structural and textural properties. The degree of ordering of the mesoporous molecular sieves modified with aluminium ions was evaluated by XRD method. The X-ray diffractograms of all correctly obtained mesoporous phases showed peaks in the small-angle range $\left(2 \Theta<10^{\circ}\right)$. The XRD profiles in the small-angle range of the ordered SBA-15 type silica are presented in Fig. 1. 
They show one intense peak at $2 \Theta \approx 1^{\circ}$ and three reflections in the range $2 \Theta \approx 1.7^{\circ}-3^{\circ}$, corresponding to the planes (100), (110) and (200) of the P6 mm structure, informing on the hexagonal ordering of the material. The intensity of all peaks was somewhat smaller for $\mathrm{Al}(30) \mathrm{SBA}-15$, which can indicate a poorer degree of its ordering than that in pure SBA-15 silica. Figure 1 also presents the XRD profiles of mesoporous SBA-16 silica modified with aluminium ions, showing one very intensive reflection at $2 \Theta \approx 1^{\circ}$, which can be assigned to the plane (110). Besides, there were a number of low-intensity peaks, informing about the ordering of the material and confirming its regular structure of the space group $\operatorname{Im} 3 \mathrm{~m}$.

The textural parameters of SBA-15 and SBA-16 type materials modified with aluminium were determined on the basis of nitrogen adsorption/desorption isotherms, and are presented in Table 1. All pure silicas and the samples modified with aluminium show well-developed surface area and large pore volume. The largest surface area was obtained for SBA-15 modified with aluminium ions in the process of synthesis (Al(60)SBA-15-940 m²/g, $\mathrm{Al}(30)$ SBA-15- $940 \mathrm{~m}^{2} / \mathrm{g}$ ). The introduction of aluminium ions into the structure of SBA-15 type silica results in an increase in the pore diameter, in $\mathrm{Al}(30) \mathrm{SBA}-15$. After modification of SBA-16 type silica, only a small increase in the pore diameter was noted, in $\mathrm{Al}(30)$ SBA- 16 .

Transmission electron microscopy was used to determine the structure of silica molecular sieves.

TEM images confirm that all materials obtained have ordered mesoporous structures (Fig. 2). The dark areas represent the pore walls and white spots reflect the empty channel spaces and pore size. Both for pristine and modified with aluminium SBA-15 material the hexagonal arrangement of pores was observed (Fig. 2a-c). It should be noted that micropores are present in the mesopore walls of SBA-15 molecular sieves. In Fig. 2d-f highly ordered regular structure of both pristine and modified with aluminium SBA-16 materials is shown.

Particle size distributions of the SBA-15 and SBA-16 type silicas modified with aluminium ions were determined by laser analyser. The results are presented in clusters corresponding to the particles of diameters from a given range. Each peak in the histogram corresponds to a certain range of particle diameters and the height of the peak indicates the percentage of particles of diameters from this range. The volume particle size distribution is studied. The statistical parameters of the distribution are calculated using the mathematically defined diameters of $d$ type $[\mathrm{m}, \mathrm{n}]$. Figure 3 presents the particle size distributions for pure and aluminium modified SBA-15 type silica. The pure SBA-15 silica shows the presence of the smallest size particles $(2-80 \mu \mathrm{m})$. With increasing amount of aluminium ions, the size of its particles increases. The percentage contribution of particles $<10 \mu \mathrm{m}$ is very small in both $\mathrm{Al}(60)$ SBA-15 and $\mathrm{Al}(30)$ SBA- 15 .

The particle size distributions for SBA-16 type silicas of regular structure and modified with aluminium do not have the Gauss curve shape (Fig. 3). The particle size distribution is very broad, which means that the samples contain particles of sizes varying in a wide range, from 2 to $100 \mu \mathrm{m}$. Table 2 presents the diameters $\mathrm{d}(0.5), \mathrm{d}(0.1)$ and $\mathrm{d}(0.9)$ for all mesoporous samples synthesised. As follows from these data, the modification of SBA-15 and SBA-16 type silicas (of different structures) with aluminium ions leads to an increase in the particle size. The highest percentage of small size particles was found in unmodified
Fig. 1 X-ray diffraction patterns in the small-angle range of the mesostructured silicas SBA-15 and SBA-16 modified with aluminium
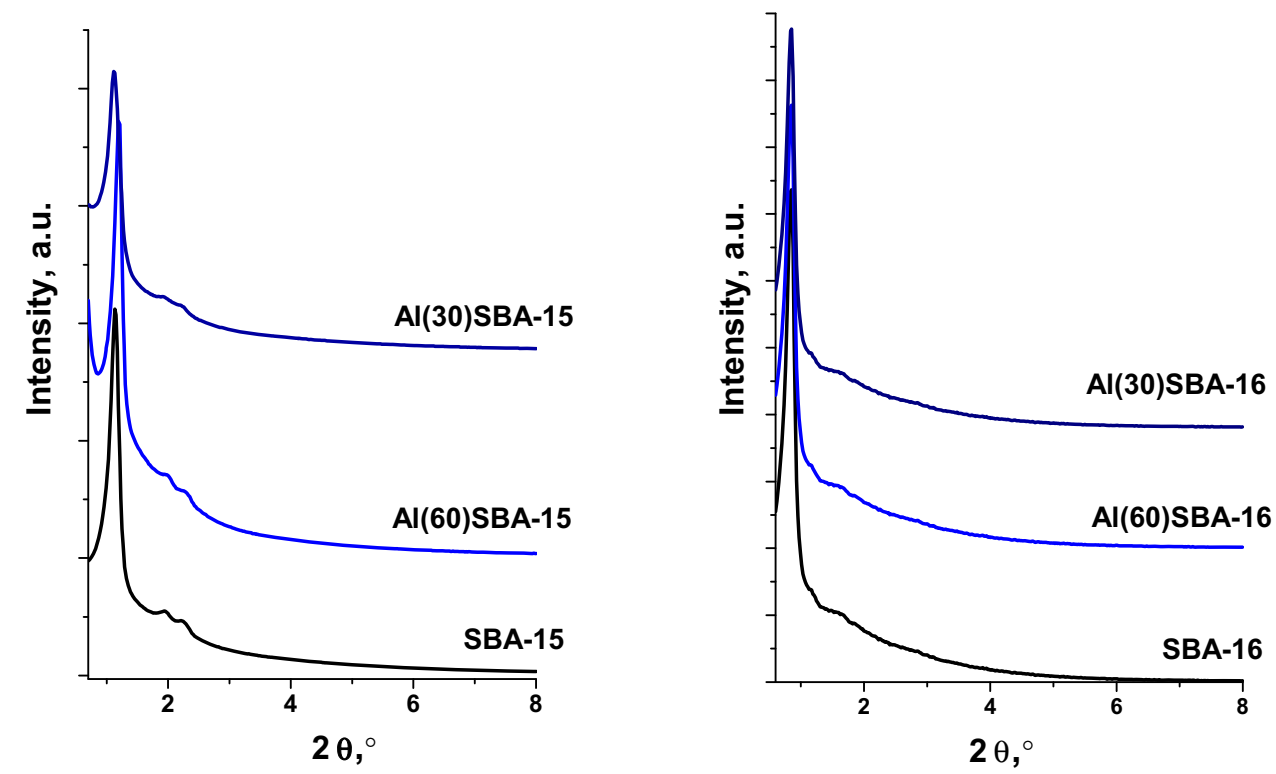
Table 1 Textural parameters of obtained materials

\begin{tabular}{lllllr}
\hline Material & $\begin{array}{l}\text { Total surface } \\
\text { area }\left(\mathrm{m}^{2} / \mathrm{g}\right)\end{array}$ & \multicolumn{2}{l}{ Pore volume $\left(\mathrm{cm}^{3} / \mathrm{g}\right)$} & $\begin{array}{l}\text { Average pore } \\
\text { diameter }(\mathrm{nm})\end{array}$ \\
\cline { 3 - 5 } & & Total & Meso & $\begin{array}{l}\text { Micro and } \\
\text { submeso }\end{array}$ & \\
\hline SBA-15 & 800 & 0.89 & 0.76 & 0.12 & 8.99 \\
$\mathrm{Al}(60)$ SBA-15 & 940 & 1.13 & 0.99 & 0.19 & 9.01 \\
$\mathrm{Al}(30)$ SBA-15 & 940 & 0.92 & 0.78 & 0.20 & 10.43 \\
SBA-16 & 740 & 0.51 & 0.39 & 0.15 & 6.35 \\
Al(60)SBA-16 & 860 & 0.61 & 0.46 & 0.20 & 6.35 \\
Al(30)SBA-16 & 870 & 0.62 & 0.49 & 0.19 & 7.09 \\
\hline
\end{tabular}
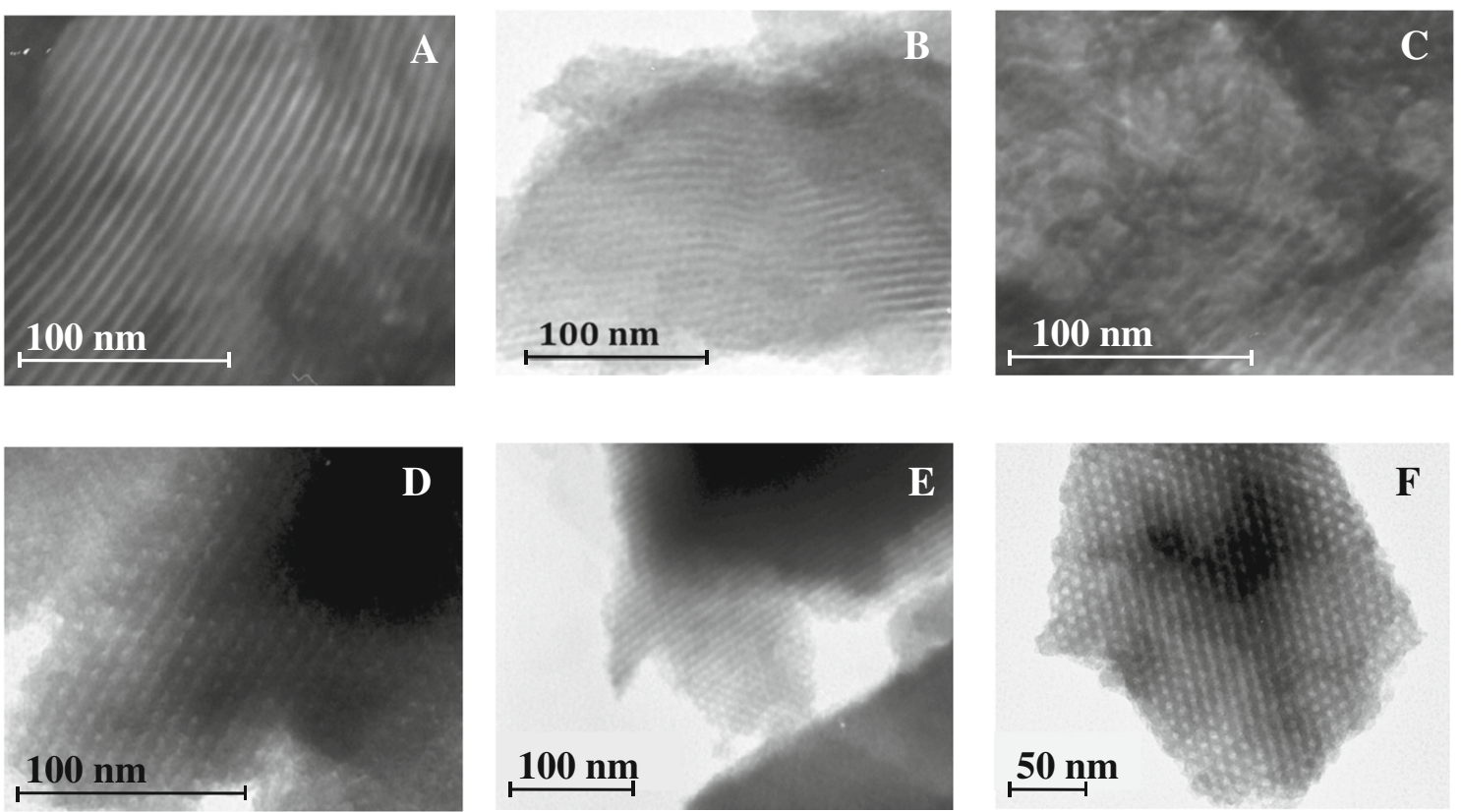

Fig. 2 TEM micrographs of: SBA-15 (a), Al(60)SBA-15 (b), Al(30)SBA-15 (c), SBA-16 (d), Al(60)SBA-16 (e), Al(30)SBA-16 (f)

silicas. SBA-16 type silica of regular structure contains larger particles than SBA-15 type sample showing hexagonal ordering.

In order to determine the morphology and particle size of mesoporous silicas SBA-15 and SBA-16 unmodified and modified with aluminium, their scanning electron microscopy images were taken. Both pristine and modified with aluminium SBA-15 materials are composed of spindle-shaped particles, which twist and wrap around each other to form larger agglomerates (Fig. 4a-c). SBA-16 silicas have irregular shaped particles (Fig. 4d-f). Their particle size is much larger than that of SBA-15 materials, which is in accordance with the results obtained by laser diffraction technique.

\subsection{L-His loading and release profiles}

Both pristine mesoporous materials and those modified with aluminium were tested in the process of L-His adsorption and release. It was reported by Vinu et al. (2006) that the highest sorption capacity towards L-His was detected at $\mathrm{pH} 7.5$, that is close to its isoelectric point. It is known that at low $\mathrm{pH}$ the histidine molecule becomes positively charged and at high $\mathrm{pH}$ is negatively charged. At isoelectric point the amino acid has zero net charge, there are both charged amino and carboxyl groups (Fig. 5). Therefore, the adsorption process of this amino acid onto mesoporous materials was performed in phosphate buffer at $\mathrm{pH}$ 7.5. It is believed that at this $\mathrm{pH}$ the electrostatic interaction between the L-His molecule and mesoporous material are negligible that enables more intensive adsorption of L-His than at other $\mathrm{pH}$ values (Goscianska et al. 2013b).

The release of L-His from mesoporous materials was carried out for $4 \mathrm{~h}$ in the potassium phosphate buffer solution at $\mathrm{pH} 7.5$ close to the isoelectric point of this amino acid. The results are depicted in Figs. 6 and 7. 
Fig. 3 Particle size distribution of mesoporous silica materials
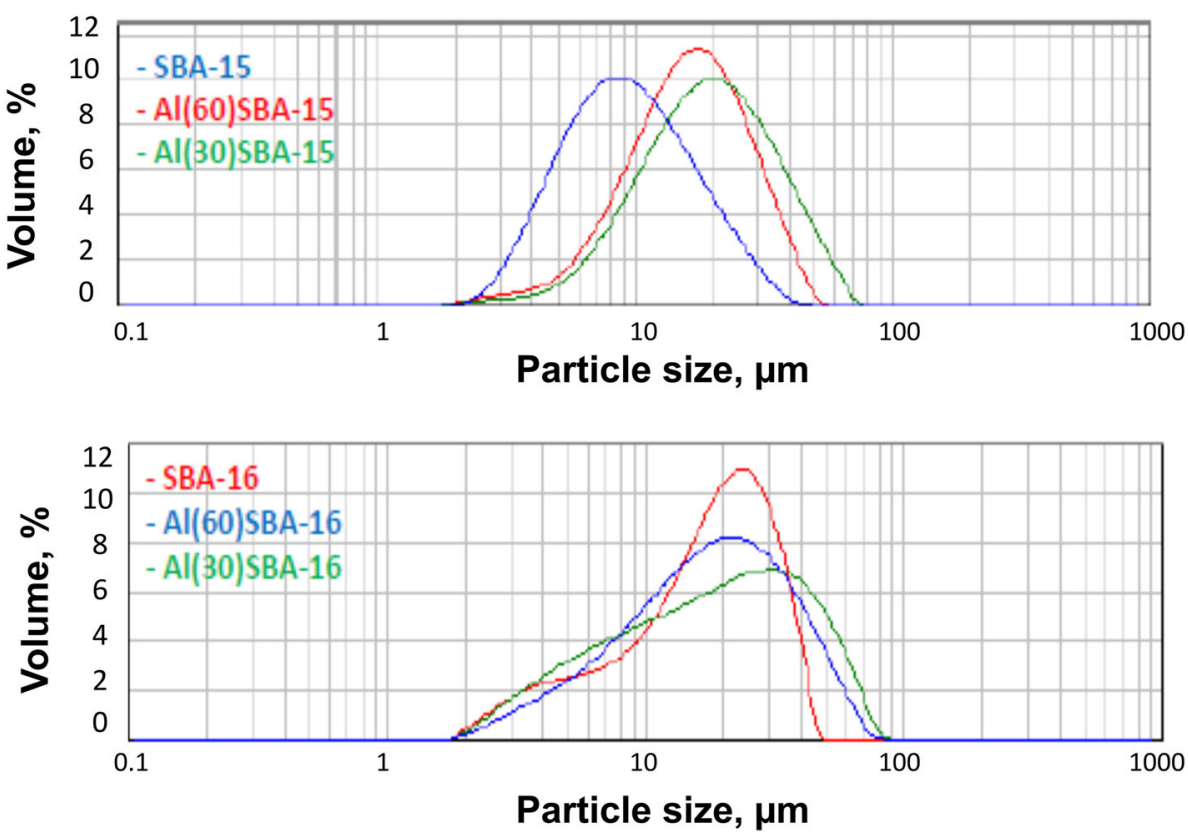

Table 2 Particle size distribution data of mesoporous silica materials

\begin{tabular}{llcl}
\hline Material & $\mathrm{d}(0.1)$ & $\mathrm{d}(0.5)$ & $\mathrm{d}(0.9)$ \\
\hline SBA-15 & 4.53 & 9.23 & 20.18 \\
Al(60)SBA-15 & 7.81 & 16.51 & 30.97 \\
Al(30)SBA-15 & 8.80 & 19.60 & 40.71 \\
SBA-16 & 5.06 & 18.10 & 32.94 \\
Al(60)SBA-16 & 5.93 & 18.05 & 41.37 \\
Al(30)SBA-16 & 4.92 & 18.70 & 48.00 \\
\hline
\end{tabular}

Aluminium-modified SBA-15 exhibited higher release rate than the pristine material. It was shown that the amount of aluminium ions introduced to the mesoporous materials strongly influenced the release rate of L-His. The release rate of L-His decreased in the sequence $\mathrm{Al}(30)$ SBA$15>\mathrm{Al}(60)$ SBA-15 $>$ SBA-15. With increasing amount of $\mathrm{Al}$ species in SBA-15 materials, pore size diameter raises which result in high percentage release of L-His.

After $4 \mathrm{~h}$ around $97 \mathrm{wt} \%$ of the amino acid was released from $\mathrm{Al}(30) \mathrm{SBA}-15$. We suggest that for SBA-15 higher amount of L-His was packed inside the intrawall micro- and mesopores as compared to the aluminium-modified materials. Therefore, the amino acid molecules, which were inside the pores, were released slower to the receptor fluid. For aluminium-containing materials the L-histidine was mostly adsorbed on the outer surface of these materials and in the bigger intrawall micropores (i.e. submesopores) and thus the amino acid could be rapidly released within first $2 \mathrm{~h}$ of the experiment. In a paper of Shin et al. (2001) it was reported that in SBA-15 the intrawall interconnecting mesopores are created by the growth and enlargement of intrawall micropores. Additionally, the interconnected nature of the mesocage pore system of SBA-16 prepared at $100{ }^{\circ} \mathrm{C}$ has recently been evidenced independently (Kim et al. 2005). It is worth noting that for aluminium modified materials with increasing submesopore volume, the pore size increases.

The opposite phenomenon was observed for the release of L-His from pristine and modified SBA-16 materials. With increasing percentage content of aluminium, the release rate of amino acid decreased in the sequence SBA$16>\operatorname{Al}(60)$ SBA-16 $>\operatorname{Al}(30)$ SBA-16. Greater amount of L-His was released from SBA-16 materials than from SBA15 samples. This could be explained by smaller pore volume of SBA-16 samples than SBA-15 materials (Table 1). According to our previous studies (Goscianska et al. 2013b) the materials with smaller pore diameter such as SBA-16 were characterised by poor adsorption capacity. We suggest that L-histidine was mainly adsorbed on the surface of these materials, therefore the release process of the biomolecule was faster when compared to that from SBA-15 samples.

Additionally, it should be mentioned that different release rate of L-His could be explained by the structural differences in the mesoporous silicas studied. Cubic arrangement of mesopores was determined for SBA-16 and hexagonal structure was observed for SBA-15 materials. The results obtained proved that the structural parameters of mesoporous materials and the percentage content of aluminium strongly influenced the release rate of L-His.

The kinetics models used to describe the L-His release from various materials are presented in Table 3. In order to understand the mechanism of amino acid release from mesoporous samples, the results were fitted with various 

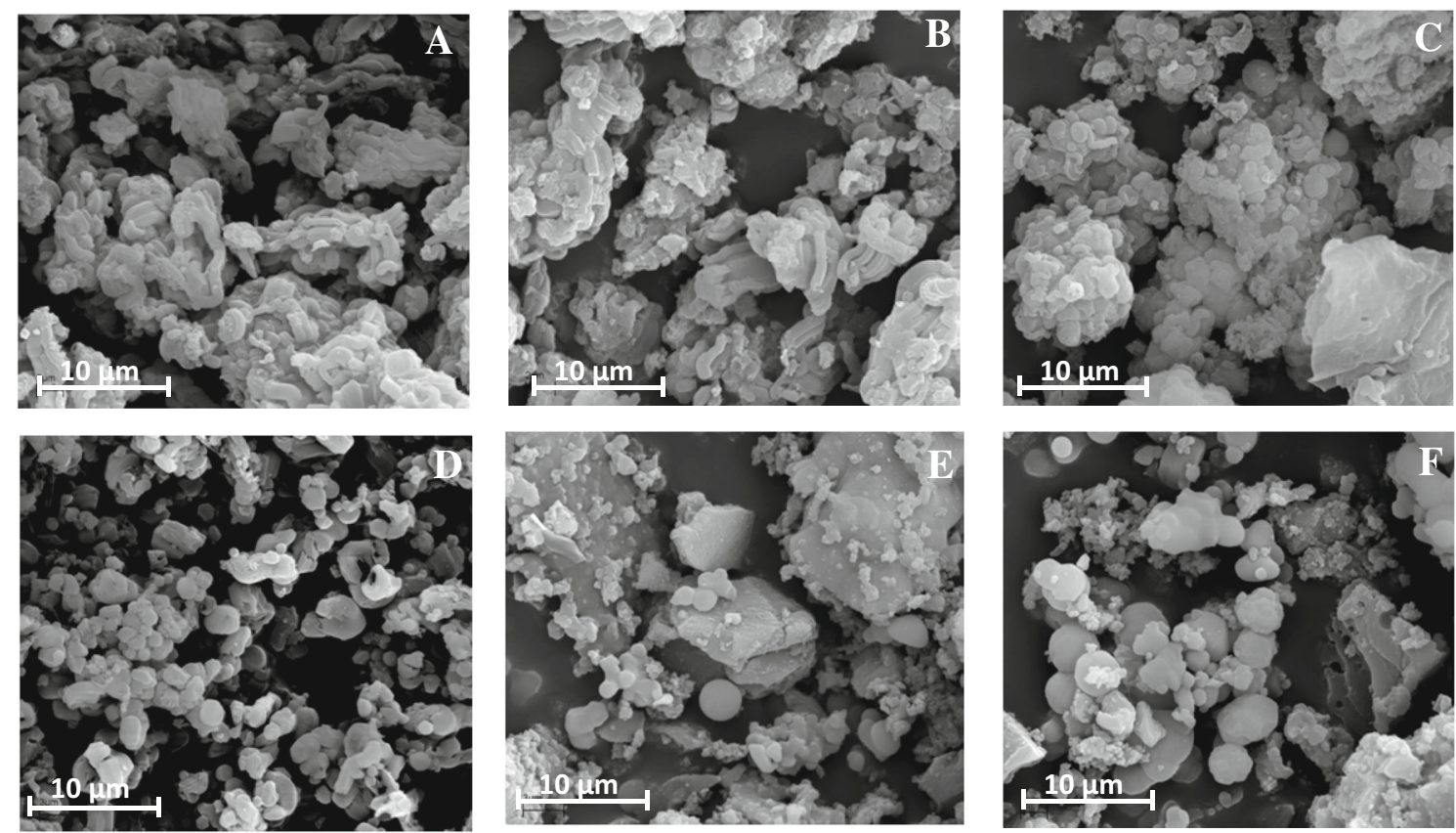

Fig. 4 SEM micrographs of : SBA-15 (a), Al(60)SBA-15 (b), Al(30)SBA-15 (c), SBA-16 (d), Al(60)SBA-16 (e), Al(30)SBA-16 (f)

Fig. 5 L-His dissociation equilibrium

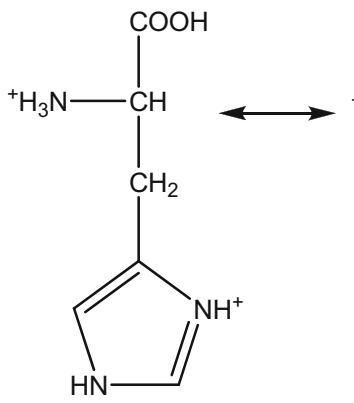

below $\mathrm{pH} 1.8$<smiles>[CH2]CC([NH3+])C(=O)C(=O)[O-]</smiles>

between $\mathrm{pH} 1.8$ and 6.0<smiles>NC(Cc1c[nH]cn1)C(=O)[O-]</smiles>

between pH 6.0 and 9.3

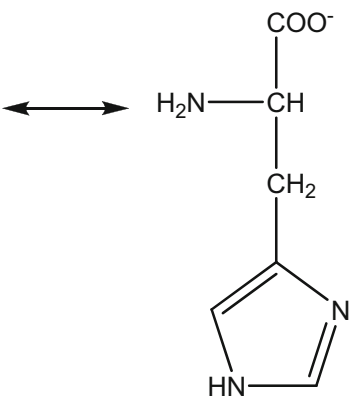

above $\mathrm{pH} 9.3$

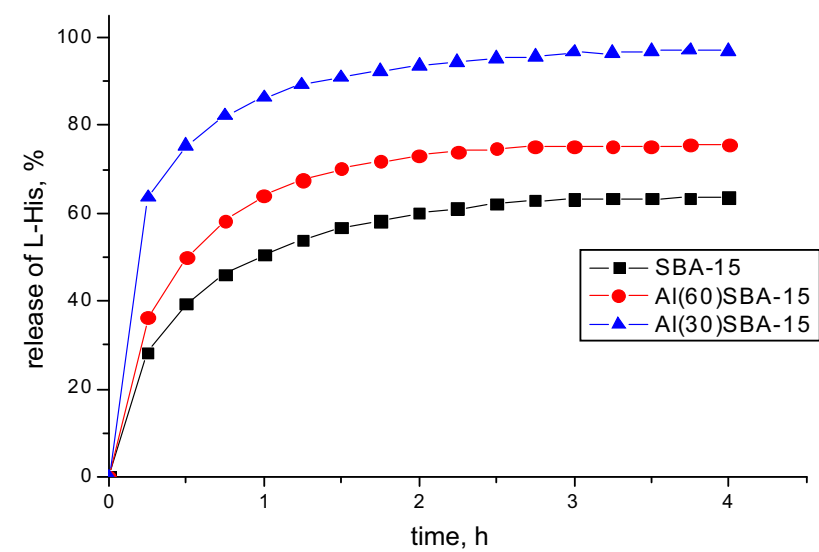

Fig. 6 Percentage of L-His released from mesoporous silica SBA-15 unmodified and modified with aluminium

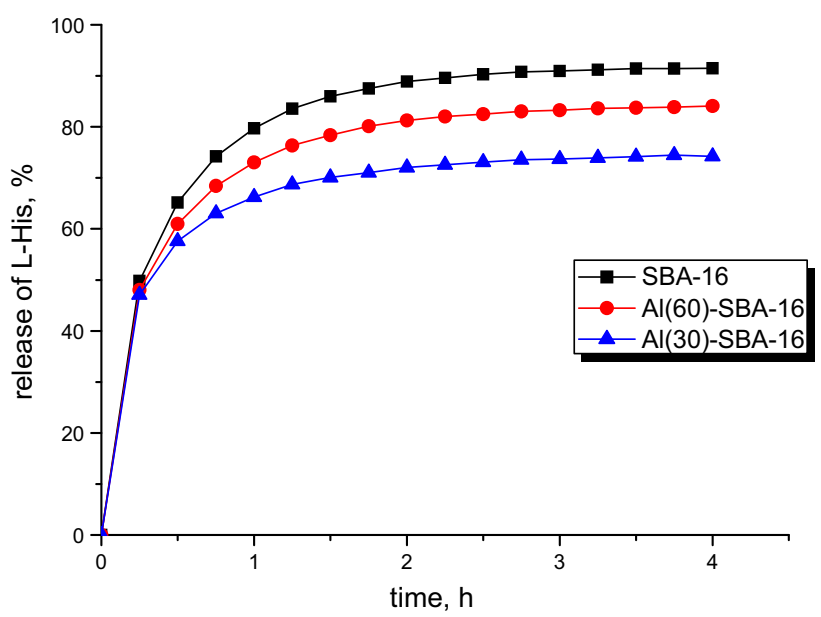

Fig. 7 Percentage of L-His released from mesoporous silica SBA-16 unmodified and modified with aluminium 
Table 3 Kinetics models used to describe the L-His release from various materials

\begin{tabular}{|c|c|c|c|c|c|c|}
\hline \multirow[t]{2}{*}{ Type of material } & Zero kinetics order & First kinetics order & \multirow[t]{2}{*}{ Higuchi model } & \multicolumn{2}{|c|}{ Korsmeyer-Peppas model } & \multirow[t]{2}{*}{ Type of transport } \\
\hline & \multicolumn{2}{|c|}{ Regression coefficient $\left(\mathrm{R}^{2}\right)$} & & \multicolumn{2}{|l|}{$\mathrm{n}$} & \\
\hline SBA-15 & 0.894 & 0.939 & 0.963 & 0.979 & 0.355 & Fickian diffusion \\
\hline $\mathrm{Al}(60)-\mathrm{SBA}-15$ & 0.861 & 0.931 & 0.941 & 0.967 & 0.337 & Fickian diffusion \\
\hline $\mathrm{Al}(30)-\mathrm{SBA}-15$ & 0.848 & 0.973 & 0.932 & 0.974 & 0.184 & Fickian diffusion \\
\hline SBA-16 & 0.844 & 0.958 & 0.930 & 0.964 & 0.275 & Fickian diffusion \\
\hline $\mathrm{Al}(60)-\mathrm{SBA}-16$ & 0.854 & 0.938 & 0.937 & 0.970 & 0.250 & Fickian diffusion \\
\hline $\mathrm{Al}(30)-\mathrm{SBA}-16$ & 0.830 & 0.89 & 0.919 & 0.963 & 0.200 & Fickian diffusion \\
\hline
\end{tabular}

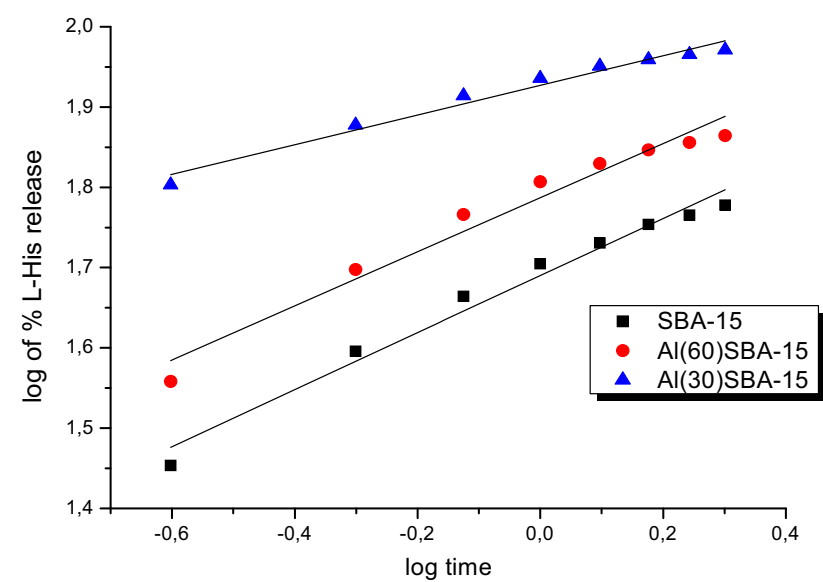

Fig. 8 Korsmeyer-Peppas model release kinetics of L-His from pristine and modified SBA-15 materials

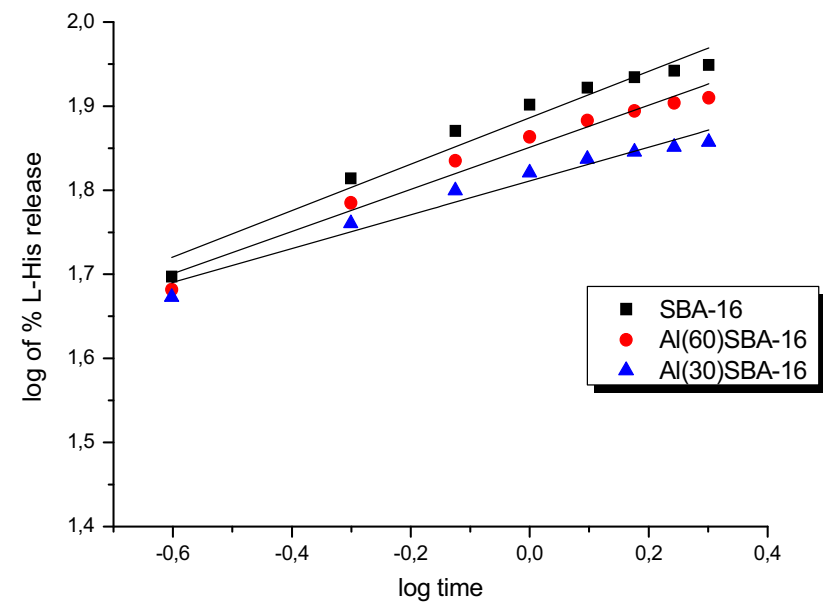

Fig. 9 Korsmeyer-Peppas model release kinetics of L-His from pristine and modified SBA-16 materials

kinetics equations such as zero order, first order, Higuchi's model and Korsmeyer-Peppas model (Sahoo et al. 2012). The highest values of regression coefficient was observed for the Korsmeyer-Peppas model, which means that the release of L-His followed this kinetics equation. Figures 8 and 9 present the fit of L-His release profiles to the Korsmeyer-Peppas model. This model enables determination if the release mechanism is Fickian diffusion or non-Fickian diffusion, on the basis of the $n$ value. According to Table 3, the $n$ values for all materials were below 0.5 , which indicates the Fickian diffusion mechanism.

\section{Conclusions}

Mesoporous materials modified with different amounts of aluminium ions were obtained by the hydrothermal method. XRD patterns and TEM images confirmed wellordered arrangement of mesopores in all samples used in this study. All pure silicas and aluminium modified samples showed well-developed surface area and high pore volume. Introduction of aluminium ions into the mesoporous silicas resulted in an increase in surface area, both for SBA-15 and SBA-16 type silicas. Furthermore, the aluminium-modified samples contained particles of greater size than the pure samples of SBA-15 and SBA-16. Biologically active molecule such as L-His was successfully loaded and released from the silicas unmodified and modified with aluminium ions. The release kinetics of amino acid followed the Korsmeyer-Peppas model. Aluminium-modified SBA-15 exhibited higher percentage of L-His released than the pristine material. On the other hand, the opposite phenomenon was observed when L-His was released from pristine and modified SBA-16 materials. The results obtained proved that the structural parameters of mesoporous materials and the percentage content of aluminium strongly influenced the release rate of L-His.

Open Access This article is distributed under the terms of the Creative Commons Attribution 4.0 International License (http://crea tivecommons.org/licenses/by/4.0/), which permits unrestricted use, distribution, and reproduction in any medium, provided you give appropriate credit to the original author(s) and the source, provide a link to the Creative Commons license, and indicate if changes were made. 


\section{References}

Blumen, S.R., Cheng, K., Ramos-Nino, M.E., Taatjes, D.J., Weiss, D.J., Landry, C.C., Mossman, B.T.: Unique uptake of acidprepared mesoporous spheres by lung epithelial and mesothelioma cells. Am. J. Respir. Cell Mol. 36, 333-342 (2007)

Chen, Y., Chen, H., Shi, J.: In vivo bio-safety evaluations and diagnostic therapeutic applications of chemically designed mesoporous silica nanoparticles. Adv. Mater. 25, 3144-3176 (2013)

Dash, S., Murthy, P.M., Nath, L., Chowdhury, P.: Kinetic modeling on drug release from controlled drug delivery systems. Acta Pol. Pharm. 67, 217-223 (2010)

Feng, Z., Li, Y., Niu, D., Li, L., Zhao, W., Chen, H., Li, L., Gao, J., Ruan, M., Shi, J.: A facile route to hollow nanospheres of mesoprous silica with tunable size. Chem. Commun. 23, 2629-2631 (2008)

Gao, Q., Xu, W., Xu, Y., Wu, D., Sun, Y., Deng, F., Shen, W.: Amino acid adsorption on mesoporous materials: influence of types of amino acids, modification of mesoporous materials and solution conditions. J. Phys. Chem. B 112, 2261-2267 (2008)

Goscianska, J., Olejnik, A., Pietrzak, R.: Adsorption of L-phenylalanine onto mesoporous silica. Mat. Chem. Phys. 142, 586-593 (2013a)

Goscianska, J., Olejnik, A., Pietrzak, R.: In vitro release of Lphenylalanine from ordered mesoporous materials. Microporous Mesoporous Mater. 177, 32-36 (2013b)

Goscianska, J., Olejnik, A., Pietrzak, R.: Comparison of ordered mesoporous materials sorption properties toward amino acids. Adsorption 19, 581-588 (2013c)

Goscianska, J., Olejnik, A., Nowak, I., Marciniak, M., Pietrzak, R.: Ordered mesoporous silica modified with lanthanum for ibuprofen loading and release behaviour. Eur. J. Pharm. Biopharm. 94, 550-558 (2015)

Hoffmann, F., Cornelius, M., Morell, J., Froeba, M.: Silica-based mesoporous organic-inorganic hybrid materials. Angew. Chem. 45, 3216-3251 (2006)

Hudson, S.P., Padera, R.F., Langer, R., Kohane, D.S.: The biocompatibility of mesoporous silicates. Biomaterials 29, 4045-4055 (2008)

Hussain, M., Fino, D., Russo, N.: Development of modified KIT-6 and SBA-15 spherical supported $\mathrm{Rh}$ catalysts for $\mathrm{N}_{2} \mathrm{O}$ abatement: from powder to monolith supported catalysts. Chem. Eng. J. 238, 198-205 (2014)

Jaroniec, M., Kruk, M., Olivier, J.P.: Standard nitrogen adsorption data for characterization of nanoporous silicas. Langmuir 15, 5410-5413 (1999)
Kim, T.W., Ryoo, R., Gierszal, K.P., Jaroniec, M., Solovyov, L.A., Sakamoto, Y., Terasaki, O.: Characterization of mesoporous carbons synthesized with SBA-16 silica template. J. Mater. Chem. 15, 1560-1571 (2005)

Kruk, M., Jaroniec, M., Sayari, A.: Application of Large Pore MCM41 molecular sieve to improve pore size analysis using nitrogen adsorption measurements. Langmuir 13, 6267-6273 (1997)

Luan, Z., Cheng, C.F., Zhou, W., Klinowski, J.: Mesopore molecular sieve MCM-41 containing framework aluminum. J. Phys. Chem. 99, 1018-1024 (1995)

Luan, Z., Hartmann, M., Zhao, D., Zhou, W., Kevan, L.: Aluminaton and ion exchange of mesoporous SBA-15 molecular sieves. Chem. Mater. 11, 1621-1627 (1999)

Mai, W.X., Meng, H.: Mesoporous silica nanoparticles: a multifunctional nanotherapeutic system. Intergr. Biol. (Camb) 5, 19-28 (2013)

Mamaeva, V., Sahlgren, C., Linden, M.: Mesoporous silica nanoparticles in medicine - recent advances. Adv. Drug Deliv. Rev. 65, 689-702 (2013)

O’Connor, A.J., Hokura, A., Kisler, J.M., Shimazu, S., Stevens, G.W., Komatsu, Y.: Amino acid adsorption onto mesoporous silica molecular sieves. Sep. Purif. Technol. 48, 197-201 (2006)

Perego, C., Millini, R.: Porous materials in catalysis: challenges for mesoporous materials. Chem. Soc. Rev. 42, 3956-3976 (2013)

Sahoo, S., Chakraborti, C.K., Behera, P.K.: Development and evaluation of gastroretentive controlled release polymeric suspensions containing ciprofloxacin and carbopol polymers. J. Chem. Pharm. Res. 4, 2268-2284 (2012)

Shin, H.J., Ryoo, R., Kruk, M., Jaroniec, M.: Modification of SBA-15 pore connectivity by high-temperature calcination investigated by carbon inverse replication. Chem. Commun. 4, 349-350 (2001)

Sobczak, I., Goscianska, J., Ziolek, M., Grams, J., Verrier, C., Bazin, P., Marie, O., Daturi, M.: WGS and reforming properties of NbMCM-41 materials. Catal. Today 114, 281-286 (2006)

Taguchi, A., Schuth, F.: Ordered mesoporous materials in catalysis. Microporous Mesoporous Mater. 77, 1-45 (2005)

Vinu, A., Hossain, K.Z., Satish Kumar, G., Ariga, K.: Adsorption of 1-histidine over mesoporous carbon molecular sieves. Carbon 44, 530-536 (2006)

Walcarius, A.: Mesoporous materials-based electrochemical sensors. Electroanalysis 27, 1303-1340 (2015)

Xia, Y., Mokaya, R.: Aluminosilicate MCM-48 materials with enhanced stability via simple post-synthesis treatment $\mathrm{n}$ water. Microporous Mesoporous Mat. 68, 1-10 (2004) 